\title{
Discussion on the Enlightenment of the Development of Game Theory to Mathematical Quality Education
}

\author{
Fengjun Yan \\ Department of Foundation, Xian Siyuan University, Xian 710038 , China
}

Keywords: Game Theory; Mathematics Quality; Education

\begin{abstract}
Game theory is a method. It has been widely used in various fields such as economics, politics, and military. From the perspective of pedagogy, game theory advocates the cultivation of students' practical problem solving abilities. Next, mathematics literacy education should break through the original "instillation" education model and enhance the students' ability to solve problems with more practical education methods so that students can achieve better mathematics learning results. This article first elaborates the theory of game theory, and then analyzes the influence of game theory development on math literacy education. Finally, we interpret the revelation of game theory to mathematics literacy education.
\end{abstract}

\section{Introduction}

Game theory is often referred to as game theory. It is a branch of modern mathematics, and it is an important subject. It mainly studies mathematical theory with competitive phenomena and guides people to analyze some practical issues from a technical perspective. For mathematics literacy education, game theory plays an important role in value, can promote students' good literacy, enable students to have certain problem-solving abilities, and master more problem solving methods. The following is a study on the implications of game theory for math literacy education. It aims to further strengthen the effect of math literacy education and improve the level of math literacy education.

\section{Game Theory Overview}

In 1994, Nash, Selten, and Haisani each received the "game theory" expert award. Game theory is a method. It has been widely used in various disciplines. Among them, game theory is most widely used in economics. Success, the cause of success cannot be separated from the efforts of economists. For example, Wilson, Krips and other scholars promoted the development of game theory by introducing dynamic analysis into game theory during the course of research work. Compared with other academic theories, game theory pays more attention to the interaction between decision-making subjects and other decision-making subjects. It can be divided into two types: cooperative games and non-cooperative games. Today, after several years of development, game theory has gradually become the core curriculum of the economics system. The Chinese mathematics community has also begun to increase the attention to the theory of game theory. Since 1998, it has organized several lectures on game theory.

\section{The Effect of Game Theory Development on the Quality of Mathematics Education}

Mathematics education is mainly studying the laws of mathematics. Quality education is a talent training model for each individual student. Students are required to learn to understand, learn to do, and learn to survive. The development of game theory is the frontier of the development of mathematical quality education. Its influence on mathematics literacy education is mainly reflected in the following aspects:

First, the application of mathematics is an important direction of mathematics literacy education. It only stays on practice exercises and often fails to achieve a good mathematical education effect. The emergence of game theory solves this problem. Its application in mathematics classes can be The application of mathematics is closely linked with social development, fundamentally changing the problem of neglecting the application of mathematics education. 
Second, teachers are leaders and organizers of mathematics classrooms. Their own quality is related to the effect of mathematics quality education. In response to this, game theory gives some inspiration. It encourages teachers to deeply study the interaction between mathematics and the development of other disciplines during the development of practical educational activities [1].

Third, the driving force of game theory is innovation. This outstanding feature has brought certain enlightenment to mathematics quality education. It guides teachers to focus on cultivating student innovation in the mathematics class and strengthen the cultivation of innovative talents and practical talents.

\section{The Development of Game Theory for Quality Education in Mathematics}

\section{Take Practical Teaching}

Game theory development has closely linked mathematics applications with social development. Therefore, in order to better highlight the educational characteristics of the application of mathematical disciplines.

For example, in the process of mathematics teaching activities, game theory can be introduced into it. A relatively common modeling case is given to the students first. Afterwards, the students are guided to build a multi-step decision model based on the content of the case. Here, the multi-step decision model is a repeated game process based on game theory. It can use $\mathrm{x}, \mathrm{y}$, and other data to represent the relevant parameters in the multi-step decision model. Finally, the problem is solved through the process of repeated games. Become a good practical ability. When the repeated game process is established, it is necessary to clarify the steps for establishing the game process. Then, give a specific benefit matrix. Finally, choose the best solution to the problem.

For another example, in the teaching of "probability" knowledge in mathematics classes, the classic prisoner's dilemma game model can be introduced. Assume that there are two criminals. When the two criminals simultaneously confess the facts of the crime, they may be sentenced to five years of imprisonment. When the two criminals fail to confess the facts of the crime, they may be sentenced to one year's imprisonment if the evidence is insufficient. . When one person does not explain and one person confesses, he may be sentenced to a non-accountable person, and the person who confesses will be released without charge. The design of this classic game model not only closely links with the reality of prison sentence sentencing in the society, but also guides students to think deeply about the probability of mathematics and plays a role in promoting students' ability to apply mathematics knowledge.

That is, game theory is a branch of mathematics. It has a certain degree of operability. Introducing the game model into the classroom can change the original mathematics classroom teaching model that focuses on theoretical indoctrination and develop students with more practical educational methods. The literacy of mathematics subjects encourages students to learn to solve practical problems in the specific learning process of mathematics knowledge. They are good at observing the surrounding environment, and ultimately achieve the knowledge learning effect of "learning from application". They no longer remain in the state of rote learning and have a better experience. The discipline of mathematics.

\section{Enrich the Quality of Educational Materials}

In the development of game theory, it began to advocate that teachers focus on the interaction between mathematics and the development of other disciplines. In this enlightenment, we should actively enrich the quality of mathematics education materials, so that students can achieve a better quality of mathematics.

For example, in the mathematics quality education activities, the mathematical concept of "moving into a line and moving into a line" is introduced as a primer in the "Chinese Kung Fu". In the process of enjoying the relaxed and pleasing music songs, students can truly understand the description of the point, line, and face of the Chinese martial arts, and then achieve a good learning effect in a good atmosphere, and cultivate a certain mathematical subject accomplishment [2].

Again, in the specific development of mathematics quality education activities, beautiful prose can be used as an introduction to mathematics classroom teaching. That is, the use of multimedia 
teaching tools for students to start language textbook content, and then through the courseware demonstration for students to interpret the mathematical problems contained in the text. For example, geometric problems? Problems with straight lines and circles? Or is it a positional relationship? And so on, aroused students' interest in mathematics knowledge, fell in love with mathematics learning, and actively participated in classroom discussion in a literary and interesting environment, and slowly developed a good mathematical discipline.

Whether it is mathematics, language, or music, each discipline has its own unique regularity. However, under the premise of subject teaching, in order to better implement mathematics quality education for students, we should combine game theory with the interaction of various disciplines to enrich the content of mathematics quality education. That is to say, the integration of Chinese language knowledge elements into mathematics quality education will allow mathematics knowledge to be presented in forms such as prose and songs. It will no longer appear to be monotonous and boring. It will also strengthen students' memory in a certain degree and make mathematics education closer to reality. Life, so that students learn to apply mathematical knowledge, to develop good mathematics learning habits [3]. In short, under the auspices of game theory, the interaction between mathematics disciplines and other disciplines in mathematics quality education should be well grasped in order to achieve a better effect of quality education and to cultivate more compound talents.

\section{Strengthen the Awareness of Innovation}

Innovation is the driving force for the development of game theory. It brings some inspiration to mathematics quality education. In today's mathematics quality education activities, we should strengthen the cultivation of students' innovative spirit, develop students' innovative ability, and finally achieve the goal of mathematics quality education.

For example, under the guidance of game theory, in order to further enhance the effect of mathematics quality education, students can be guided to answer questions in accordance with the general problem-solving ideas. Then, encourage students to think from different angles, think about the conditions that are known in the problem, apply them comprehensively, and so on. Here, teachers should no longer restrain students from adopting routine solutions. As a result, students are encouraged to gradually develop good differences and have a certain ability to think.

For example, in mathematics education activities, it is impossible to adopt a previous education method to present students with a theorem, which requires students to voluntarily demonstrate the accuracy of standards. This makes it difficult to develop students' innovative thinking. It should try to combine mathematics classroom teaching content to create some situations for students. The classroom situation stimulates students to explore their desires and make students' interest in learning grow. Then, contact the classroom situation to ask students to observe a certain mathematics law, make the best use of the situation, active student thinking, and inspire students to explore what they have learned in class [4]. This kind of education can enable students to maintain a joyful learning mood and fully excavate students' creative abilities so that they can develop their mathematics qualities better.

Under the guidance of game theory, the development of mathematics quality education activities should try to give students some room for questioning, so that students dare to question, and then in the process of questioning, they have the desire to learn mathematics knowledge and devote themselves to the process of question solving. Solve mathematics problems, sum up some suitable learning methods, and slowly develop good innovation spirit [5].

However, throughout the education process, teachers should first possess a certain degree of innovative spirit, invest a certain amount of energy in the planning of the talent cultivation model, and then achieve better educational results through the scientific deployment of mathematics quality education activities. In the past, mathematics quality education emphasized only the cultivation of computational capabilities, spatial imagination, and logical thinking. Today, under the guidance of game theory, we should fully consider innovative spiritual education, truly achieve the goal of mathematical quality education, fully demonstrate the game theory's enlightenment in mathematics quality education activities, and carry out quality education reform work in depth. 


\section{Conclusion}

We can see that the effect of mathematics literacy education is not ideal at this stage. Under this background, we should combine the enlightenment brought by the development of game theory to innovate the current mathematical literacy education model and use a more practical education method. It guides students to learn to establish relevant mathematical models in the process of learning mathematics knowledge, and then summarizes the correct answers to mathematical problems by observing and analyzing the mathematical models. Throughout the entire process, not only students' mathematics thinking can be activated, but also students' problem-solving abilities can be exercised. Students can better internalize the knowledge learned in the classroom and develop good mathematics disciplines.

\section{References}

[1] Manuela Alves, Cristina S. Rodrigues, Ana Maria A.C. Rocha, Clara Coutinho. Self-efficacy, mathematics' anxiety and perceived importance: an empirical study with Portuguese engineering students[J]. European Journal of Engineering Education, 2016. 8. 31, issue 1, 11.

[2] Horn, Kane. Opportunities for Professional Learning in Mathematics Teacher Workgroup Conversations: Relationships to Instructional Expertise[J]. Journal of the Learning Sciences, 2015,10, 10, issue 3, 15.

[3] Garabed Eknoyan. Clinical Trials in Uremia-Time to Reappraise[J]. Journal of Renal Nutrition, 2015, 10,23, issue 2:15.

[4] Anake Sudejamnong, Kittipot Robsouk, Suladda Loipha, Maitree Inprasitha. Development of Teachers' Mathematical Knowledge for Teaching by Using the Innovation of Lesson Study and Open Approach[J]. Sociology Mind, 2014, 10, 21, issue 4: 15-21.

[5] N Belinskaya, E Ivanchina, E Ivashkina, E Frantsina, G Silko. Mathematical model of straight run diesel catalytic hydroisomerization[J]. IOP Conference Series: Earth and Environmental Science, 2014, 5, 6, issue 1, 21.

[6] Yu D, Peng L. When does Inferring Reputation Probability Countervail Temptation in Cooperative Behaviors for the Prisoners' Dilemma Game? [J]. Chaos, Solitons \& Fractals, 2015, 78: 238-244. 